\title{
REVIEW \\ Effects of dispersal plasticity on population divergence and speciation
}

\author{
JD Arendt
}

Phenotypic plasticity is thought to have a role in driving population establishment, local adaptation and speciation. However, dispersal plasticity has been underappreciated in this literature. Plasticity in the decision to disperse is taxonomically widespread and I provide examples for insects, molluscs, polychaetes, vertebrates and flowering plants. Theoretical work is limited but indicates an interaction between dispersal distance and plasticity in the decision to disperse. When dispersal is confined to adjacent patches, dispersal plasticity may enhance local adaptation over unconditional (non-plastic) dispersal. However, when dispersal distances are greater, plasticity in dispersal decisions strongly reduces the potential for local adaptation and population divergence. Upon dispersal, settlement may be random, biased but genetically determined, or biased but plastically determined. Theory shows that biased settlement of either type increases population divergence over random settlement. One model suggests that plasticity further enhances chances of speciation. However, there are many strategies for deciding on where to settle such as a best-of-N strategy, sequential sampling with a threshold for acceptance or matching with natal habitat. To date, these strategies do not seem to have been compared within a single model. Although we are just beginning to explore evolutionary effects of dispersal plasticity, it clearly has the potential to enhance as well as inhibit population divergence. Additional work should pay particular attention to dispersal distance and the strategy used to decide on where to settle.

Heredity (2015) 115, 306-311; doi:10.1038/hdy.2015.21; published online 25 March 2015

\section{INTRODUCTION}

Phenotypic plasticity is the ability of a single genotype to produce multiple phenotypes depending on environmental conditions. Several recent reviews highlight the role of phenotypic plasticity in promoting population divergence and speciation (Schlichting, 2004; Grether, 2005; Crispo, 2007; Ghalambor et al., 2007; Pfennig et al., 2010; Fitzpatrick, 2012). The growing interest in phenotypic plasticity reflects the general shift from an assumption that plasticity always inhibits evolutionary change (summarized in Schlichting and Pigliucci, 1998) to one that plasticity can accelerate change (Schlichting and Pigliucci, 1998; West-Eberhard, 1989, 2003). To date, the emphasis has been on what happens after organisms invade a new habitat or when the habitat changes. That is, how does phenotypic plasticity influence population establishment or persistence (for example, Chevin et al., 2010)? Once the population has established itself, how does plasticity influence rates and patterns of adaptation (reviewed in Paenke et al., 2007)? Finally, following local adaptation, does plasticity affect mate choice (for example, Price et al., 2003; Craig et al., 2005; Edelaar et al., 2008; Deere et al., 2012) thus promoting speciation (for example, Edelaar et al., 2008; Havens and Etges, 2013)? However, as Thibert-Plante and Hendry (2011) and Fitzpatrick (2012) have pointed out, the start of this process, which is migration to the new habitat, has been largely neglected. These authors emphasize how timing of dispersal can interact with plasticity to enhance or limit population divergence. For example, if dispersal occurs after growth is complete then developmentally plastic traits will be fixed prior to dispersal. Because cues determining the phenotype are experienced in the natal habitat, the phenotype expressed may not match the habitat where that individual settles thus restricting gene flow. In addition to this indirect effect of dispersal on the expression of plastic traits, dispersal itself is often phenotypically plastic. The decision whether or not to disperse may depend upon local conditions such as local productivity, population density, parasite load, or social context such as sex ratio or the number of relatives in a population (see Bowler and Benton, 2005; Ronce, 2007; Clobert et al., 2009 for reviews). In addition, where an individual settles once the decision to disperse has been made may depend upon local conditions or an individual's phenotype (for example, Stamps et al., 2005; Edelaar et al., 2008).

Here, I describe some empirical examples of dispersal plasticity, both in terms of plasticity in the decision whether or not to leave a natal habitat and plasticity in where one settles on doing so. This is not meant as a comprehensive review but to show that such plasticity is taxonomically widespread. Next, I examine theoretical models that explore the effect of both forms of plasticity on meta-population dynamics and local adaptation. Finally, I discuss potential approaches for testing the effects dispersal plasticity. Because effects of timing in dispersal have been considered in detail elsewhere (Thibert-Plante and Hendry, 2011; Fitzpatrick, 2012), I confine my discussion to plasticity in whether to disperse and where to settle only.

DISPERSAL PLASTICITY: WHEN TO LEAVE AND WHERE TO GO? Dispersal occurs when individuals permanently leave their natal population and settle in a new patch or population. Dispersal can be split into three overlapping phases: the decision whether or not to 
leave the natal patch, movement between patches and the decision on where to settle (Lidicker and Stenseth, 1992). Although usually modeled as a cognitive decision in which organisms assess local conditions or compare among patches, plastic genotypes can integrate information without any actual thought involved. For example, the plant Heterosperma pinnatum produces high-dispersal seeds with bristles that catch in animal fur as well as low-dispersal seeds without bristles. Martorell and Martinez-Lopez (2014) show that the frequency of seeds with bristles increases with local competition and water stress, conditions that favor dispersal.

The decision to disperse is often called unconditional when it is not plastic and conditional when it is (following McPeek and Holt, 1992). In unconditional dispersal a fixed proportion of individuals disperse each generation, whereas with conditional dispersal this proportion depends on environmental conditions (reviewed in Bowler and Benton, 2005). In addition to environmental conditions, the decision to disperse may also depend on an individual's relative condition (Clobert et al., 2009) such as in brown trout (Salmo trutta) where smaller, inferior competitors are forced to disperse downstream from hatching redds to establish feeding territories (for example, Titus and Mosegaard, 1991). Both unconditional and conditional dispersal are well described in insects with wing polymorphisms. Many insect species produce both long-winged (macropterous) morphs capable of flight and short-winged (micropterous) or unwinged (apterous) morphs that cannot fly (reviews in Harrison, 1980 and Roff, 1986). In some cases expression of alternative phenotypes depends on fixed genetic differences but in other cases it has been shown to depend on environmental conditions (Zera, 2004). For example, in the streamdwelling water strider (Aquarius remigis) Fairbairn and King (2009) have shown that the frequency of macropterous individuals usually increases with temperature, a likely cue of habitat drying. Crowding is also a common factor that increases production of macropterous individuals in many insects (for example, Braendle et al., 2006; Poniatowski and Fartmann, 2009).

Although alternative dispersal morphs are best known for insects, similar patterns have been documented in a variety of organisms. Some sea slugs produce a higher frequency of widely dispersing planktotrophic larvae in winter and a higher frequency of lowdispersing lecithotrophic (non-feeding) larvae during summer months (Krug et al., 2012). Several polychaetes also produce both planktotrophic and lecithotrophic larvae (Levin et al., 1991; Morgan et al., 1999) and regulation appears to be plastic in at least one species (Gibson and Gibson, 2004) although it is not clear what environmental cue triggers this. In addition to the example of $H$. pinnatum given above, many plants produce high- and low-dispersing seed types. Crepis sancta produces wind-dispersed fruits with long tufts and non-dispersing fruits without tufts (Imbert, 1999) and the number of the former is greater under simulated herbivory and low nutrients (Imbert and Ronce, 2001). Many plants also produce subterranean (cleistogamous) flowers and seeds as well as above ground (chasmogamous) flowers and this is especially common in grasses of the Poaceae. Cheplick (2007) reviews a number of studies showing that the ratio of cleistogamous to chasmogamous flowers depends on population density and light level but apparently not on nutrient level. Plasticity may also enhance dispersal in indirect ways. For example, stem elongation is seen in many plants (Schmitt and Wulff, 1993) and is thought to be a plastic adaptation to avoid shading by competitors. Stem-elongation allows a plant to overtop its neighbors, gaining exposure to direct sunlight (Donohue et al., 2001; Weinig et al., 2004). This will also elevate flowers and enhance pollen and seed dispersal, especially for wind-dispersed species (for example, Soons et al., 2004;
Thomson et al., 2011). Thus, although the decision to disperse is often treated as dichotomous (either one leaves or one stays), conditional dispersal does not necessarily require distinct morphologies. Conditional dispersal can also be a treated as a probability of dispersal dependent on continuous traits such as stem height. Additional examples can be found in Bowler and Benton (2005) and Clobert et al. (2009).

The other aspect of dispersal is deciding on where to settle. Settlement may be random or biased, but even biased settlement need not always reflect phenotypic plasticity (Edelaar et al., 2008) such as when dispersal distance depends on sex (for example, Clarke et al., 1997). For biased settlement to be a form of phenotypic plasticity, the decision on where to settle must depend directly on the environment in some way. For example, empirical studies suggest that some animals pick patches to settle because they resemble where they grew up (reviewed in Davis and Stamps, 2004). Settlement patterns may also depend upon the organism's own physical condition, sometimes called phenotype-dependent settlement (following Clobert et al., 2009). For example, Garant et al. (2005) found that great tits (Parus major) that are heavier at fledging tend to migrate to higher-quality patches within Wytham woods, whereas those that are lighter at fledging move to lower-quality patches. A pattern where higher-quality individuals settle in higher-quality patches is sometimes called the silver-spoon effect (Stamps, 2006). Whether or not plasticity comes into the issue, individuals often seem to pick environments for which some aspect of their phenotype especially suites them. Edelaar et al. (2008) call this 'matching habitat choice' when the match enhances overall fitness.

Thus dispersal plasticity, whether in the decision to leave the natal patch or on where to settle, is taxonomically widespread and likely common. What is less clear are the consequences of such plasticity for meta-population structure, local adaptation and divergence.

\section{POPULATION GENETIC EFFECTS OF THE DECISION TO DISPERSE}

Dispersal influences population size, gene flow among populations and the degree of genetic variation available for selection. Theoretically, all of these will affect population persistence, rate of local adaptation and population divergence but the joint effects are often very complicated (Garant et al., 2007; Blanquart et al., 2012). In terms of population genetics, dispersal is thought to reduce differentiation in mean phenotype among populations, slowing or even preventing local adaptation (reviewed in Blanquart et al., 2012). For example, Hendry et al. (2002) show that stream and lake threespine stickleback (Gasterosteus aculeatus) have different morphologies adapted to their respective habitats. In the Misty Lake system, stream fish have deeper bodies and fewer gill rakers, characteristic of a benthic lifestyle. Lake fish have more fusiform bodies and more gill rakers, characteristic of limnetic fish. In Misty Lake, there is a clear division between stickleback populations in inlet streams and the lake with little gene flow. However, there is abundant gene flow from the lake to outlet streams. As a result, although we would expect fish in the outlet streams to have morphologies similar to those in inlet streams, they are actually indistinguishable from lake fish. This pattern seems to be general for stickleback stream-lake populations (Hendry and Taylor, 2004). Postma and van Noordwijk (2005) show that gene flow from the mainland ( $43 \%$ of breeders) to the west side of the island of Vlieland has prevented great tits (P. major) from evolving an optimal clutch size for island conditions. By contrast, gene flow from the mainland has not been sufficient (13\% of breeders) to prevent local adaptation on the east side of the island. However, theory shows that, under some circumstances, dispersal can increase genetic variation 
within a population thus providing the raw material for local adaptation (Blanquart et al., 2012; Edelaar and Bolnick, 2012). I don't know of empirical studies directly supporting this result but Lavergne and Molofsky (2007) provide a potential example in canarygrass (Phalaris arundinacea) and Grant and Grant (2014) provide a potential example in the large ground finch (Geospiza magnarostris). Arnold and Martin (2010) provide several examples where interspecific hybridization appears to promote adaptation and even invasion of novel habitats. For example, Rieseberg et al. (2003) describe several hybrid species of Helianthus sunflowers found in environments that their respective parental species cannot tolerate.

Theoretically, the population genetics consequences can thus be both negative and positive. Most theory on the evolution of dispersal itself has ignored plasticity (reviews in Johnson and Gaines, 1990; Payne et al., 2011), but an increasing number of models now compare conditional to unconditional strategies. Early models found that conditional strategies generally outcompete unconditional strategies (McPeek and Holt, 1992; Travis et al., 1999) but in some cases a mix of strategies could coexist (Johst and Brandl, 1997; see also Hazel et al., 2004). However, we are less interested here in the evolution of plasticity itself than in how dispersal and settlement plasticity influences evolution (following, Edelaar et al., 2008). Armsworth and Roughgarden (2008) used a stepping-stone model to determine the effects of dispersal plasticity on the formation of a genetic cline. They used a one-locus, two-allele model where alternative alleles are favored at either end of an environmental cline. For plastic dispersal, the decision whether or not to leave the natal patch depended upon a comparison of fitness (juvenile survival plus reproduction) in neighboring patches relative to the natal patch. Their major result was that, when the probability of dispersing is sensitive to local environmental conditions, a slightly steeper cline forms than when dispersal is unconditional. A steeper genetic cline suggests stronger separation between genotypes across the environmental cline-promoting local adaptation. Payne et al. (2011) modeled evolution along a continuous cline. Unlike Armsworth and Roughgarden, plastic dispersal depends only on juvenile survival rate in the natal patch, rather than a comparison among patches. In addition, dispersal distance was allowed to evolve rather than being restricted to the nearest patch. They found that conditional dispersal causes genotypes to be spread more evenly, breaking up phenotype clusters and preventing speciation. This effect appears to be driven in part by the evolution of greater dispersal distances with conditional than with unconditional dispersal (see Heinz et al., 2009 for a similar effect of dispersal distance without conditional dispersal). This might also explain why Armsworth and Roughgarden (2008) found the opposite effect of conditional dispersal when settlement was confined to neighboring patches. Thus, for the limited theoretical work available, it appears that the effect of plastic dispersal might be influenced by dispersal distance (Edelaar and Bolnick, 2012 discuss this for dispersal in general). If dispersal is restricted to neighboring patches then plasticity in the decision to disperse can slightly increase chances of local adaptation. However, for longer dispersal distances plasticity greatly decreases the chance of local adaptation and speciation.

\section{POPULATION GENETIC EFFECTS OF HABITAT SELECTION}

Habitat selection has long been considered a potential mechanism for maintaining genetic polymorphisms within meta-populations (for example, Hedrick, 1986; Barton, 1992; Ravigne et al., 2004). Settlement is usually modeled as either random or plastic, meaning individuals pick among habitats ranked by some specified criterion (Lima and Zollner, 1996). As with models of conditional dispersal, most theory has dealt with the evolution of plasticity in habitat choice (for example, Scheiner, 1998) rather than the evolutionary consequences of plasticity.

Armsworth and Roughgarden (2008) examined the effects of habitat choice as well as conditional dispersal. This was done by comparing a strategy where settlement was at random to a neighboring patch or where individuals picked the neighboring patch that would yield the highest fitness (a 'best-of-N' strategy). Habitat choice led to a very steep genetic gradient regardless of other parameter manipulations. Ravigne et al. (2009) compared several life-cycles where settlement was random or where habitat choice was allowed to evolve. When performance trade-offs between habitats were strong, a single specialist strategy evolved, which exploited only one habitat. When trade-offs were weak, random settlement lead to a generalist. In this situation, allowing habitat choice can result in the generalist splitting into two specialists adapted to each habitat, setting the stage for speciation. However, in both models the contrast was between random settlement versus a biased settlement, which was not explicitly modeled as plastic. Beltman and Metz (2005) take this factor into account and consider settlement as random, genetically determined or a learned preference. They modeled the joint evolution of an ecological trait (one that affects performance depending upon patch type), a genetically determined habitat preference, and a learned preference (in this case for the natal habitat type as in Davis and Stamps, 2004). When performance trade-offs were strong individuals evolved to specialize on one habitat with a genetic preference for that habitat similar to Ravigne et al. (2009). When trade-offs were weak then a generalist evolved with no choice, again similar to Ravigne et al. (2009). However, the generalist population now experienced disruptive selection and the intensity of disruptive selection was stronger with greater learning of habitat preference. Beltman and Metz (2005) concluded that learning (plasticity) tends to promote speciation, whereas random settlement and genetically determined habitat choice do not. Finally, dispersal distance is likely to be important with regard to habitat choice as well as for conditional dispersal although it probably does not reverse the relative importance of random and biased settlement. In a landscape model, Vuilleumier and Perrin (2006) showed that random settlement resulted in greater connectivity (that is, gene flow) among patches than when individuals settled in a preferred patch. However, increasing dispersal distance with habitat choice lead to greater connectivity among patches, although this never reached a level as high as with random settlement.

Several models have looked at the emergence and maintenance of genetic polymorphism with genetically determined habitat choice. Beltman and Metz (2005) appear to be the only model to incorporate both genetic and plastic habitat choice. Clearly, we need additional work to examine the effects of different types of habitat choice, especially the influence of different mechanisms of habitat choice. Several models such as Armstrong and Roughgarden (2008) use a 'best-of-N' strategy in which all local patches are compared. Another sampling procedure is a sequential method. Rather than sampling all nearby patches then settling in the best one, individuals have a threshold for settlement that is updated on the basis of past sampling and current condition (for example, Stamps et al., 2005). Once the threshold is reached, the individual settles even though superior but unsampled patches may exist. Finally, individuals may chose to settle in patches that match their natal habitat (Stamps and Swaisgood, 2007), a strategy that requires minimal sampling. Although 'best-of-N' type and sequential strategies have been compared in the context of mate choice (for example, Real, 1990), I am not aware of models comparing them with regard to settling decisions. I suspect that 
different sampling methods will influence how effectively genotypes get segregated among different patch types, with 'best-of-N' likely being most effective and a threshold being least, but this needs to be modeled explicitly.

Given how few theoretical studies have compared random dispersal with plastic dispersal in any of its aspects, it is clearly too early to make any firm conclusions about the role of dispersal plasticity for local adaptation and speciation. However, the papers described above offer some intriguing patterns that should be modeled more explicitly. First, it appears that dispersal distance affects whether plasticity in the decision to disperse increases or decreases genetic divergence relative to unconditional dispersal. Second, Stamps (2006) suggests that dispersal distance might influence settling strategy, especially if dispersers vary in condition. Thus actual dispersal distance might depend on individual phenotype or genotype-enhancing population divergence. Finally, biased settlement seems to favor habitat specialists over generalists (for example, Ravigne et al., 2004). If this bias is due to plasticity, either because individuals can compare patches or match habitats to prior experience, this may further enhance population divergence. This will be especially true if mating occurs after settlement in the new habitat (Edelaar et al., 2008).

\section{EMPIRICAL TESTS OF EVOLUTIONARY EFFECTS OF PLASTICITY}

Although we clearly need more models that explicitly compare plastic dispersal with non-plastic dispersal, this is no reason not to begin empirical studies of how plasticity affects evolutionary patterns and the potential for speciation. Such studies could take the form of phylogenetic comparisons, tracking genotype distribution across meta-populations, or experimental studies. As an example of phylogenetic comparisons, Pfennig and McGee (2010) showed that clades with trophic-polymorphisms tend to be more speciose than sisterclades lacking polymorphisms. This approach could be applied to clades with different dispersal strategies such as polychaetes where some species have genetically fixed determination of larval morphs (Levin et al., 1991; Morgan et al., 1999) and other species have plastic determination of morphs (Gibson and Gibson, 2004). However, this approach requires knowledge of dispersal plasticity in a large number of species for such a comparison to be effective.

Comparing genetic variation within and between populations has become routine in evolutionary genetics. Work in landscape genetics (for example, Petren, 2013) is developing tools for even more detailed analyses of population genetic structure at very fine scales. For example, using genome-wide single-nucleotide polymorphisms, Garroway et al. (2013) showed that great tits within Wytham Woods are subdivided into several distinct sub-populations and that these groupings appear to be associated with the evolution of resistance to avian malaria but not the density of oak trees (a proxy for caterpillar density, which has been shown to improve offspring production). They suggest dispersal patterns explain much of this variation. This approach could be used to explore how variation in dispersal plasticity influences very local adaptation and population differentiation. One might also predict that clustering among genotypes will depend upon dispersal plasticity. For example, some plant species have been shown to vary genetically in their stem-elongation response to competition (Donohue et al., 2001). Highly plastic genotypes will show longdistance dispersal under competition where elongate stems are favored and short-distance dispersal without competition where short but highly branched morphologies are favored. This should spread their genotypes evenly across the landscape. By contrast, genotypes with limited plasticity will always be short and show only short-distance dispersal, likely resulting in a clumped distribution.

Finally, experimental manipulations of dispersal plasticity should be possible in small species with easily defined patch use. Mites hold great promise for such studies and have been used in multi-patch studies for some time (for example, Huffacker, 1958). The two-spotted spider mite (Tetranychus urticae) has been used in experimental manipulation (for example, Bitume et al., 2013) and selection studies (for example, Franhofer et al., 2014) on dispersal. Ariel dispersal behavior in this species is conditional on food level. Selection on tendency to show dispersal behavior altered sensitivity to food deprivation ( $\mathrm{Li}$ and Margolies, 1994), indicating heritable variation for conditional dispersal. By setting up multi-patch mesocosms, then stocking mesocosms with genotypes that vary in plasticity, one could track the evolution of dispersal patterns, patch use and rates of divergence.

\section{CONCLUSIONS}

Dispersal plasticity is taxonomically widespread and I have described examples from plants, vertebrates, molluscs, polychaetes, insects and arachnids. However, as Thibert-Plante and Hendry (2011) and Fitzpatrick (2012) point out, we have explored little of the evolutionary consequences of this plasticity. Different theoretical models seem to reach different conclusions about whether plasticity in the decision to disperse increases or decreases population divergence relative to random dispersal. I suspect the difference in outcome depends in part on dispersal distance with plasticity enhancing divergence under short-range dispersal (Armsworth and Roughgarden, 2008), but inhibiting divergence under longer-range dispersal (Payne et al., 2011). However, this pattern might be very different with other assumptions (for example, Edelaar and Bolnick, 2012). Biased settlement has long been suspected to enhance genetic differentiation over random settlement because different genotypes can become associated with specific habitat types (Ravigne et al., 2004). Plasticity in habitat choice, rather than fixed genetic differences, may do an even better job of allowing polymorphisms to persist (Beltman and Metz, 2005). However, different strategies for deciding on where to settle apparently have not been compared. One factor that emerges from comparing these models is that dispersal distance, including plasticity in dispersal distance, needs to be considered more carefully than it has in the past. It is also clear that we have the necessary tools to begin examining the effects of dispersal plasticity on real organisms. This is an exciting time to be exploring the evolutionary consequences of biased dispersal in general (for example, Edelaar and Bolnick, 2012) and dispersal plasticity both theoretically and empirically.

\section{DATA ARCHIVING}

There are no data to archive.

\section{CONFLICT OF INTEREST}

The author declares no conflicts of interest.

\section{ACKNOWLEDGEMENTS}

I am greatly indebted to several anonymous reviewers who devoted much time and offered marvelous advice to repair my clumsy attempt to deal with these issues. Thanks to Johan Hollander for hosting this fascinating symposium. Thanks especially to Emilie Snell-Rood, Matthew Wund and Josh Van Buskirk for stimulating discussion and convincing me to take a more optimistic view of the role of plasticity in adaptation. Andrew Furness, Keenan Morrison and Cynthia Dick offered much advice that helped to make this manuscript more readable. 
Armsworth PR, Roughgarden JE (2008). The structure of clines with fitness-dependent dispersal. Am Nat 172: 648-657.

Arnold ML, Martin NH (2010). Hybrid fitness across time and habitats. Trends Ecol Evol 25: $530-536$.

Barton NH (1992). The genetic consequences of dispersal. In: Stenseth NC, Lidicker Jr WZ (eds). Animal Dispersal: small mammals as a model. Chapman and Hall: London, UK. pp 37-59.

Beltman JB, Metz JAJ (2005). Speciation: more likely through a genetic or through a learned habitat preference? Proc Biol Sci 272: 1455-1463.

Bitume EV, Bonte D, Ronce O, Bach F, Flaven E, Olivieri I et al. (2013). Density and genetic relatedness increase dispersal distance in a subsocial organism. Ecol Lett 16 430-437.

Blanquart F, Gandon S, Nuismer SL (2012). The effects of migration and drift on local adaptation to a heterogeneous environment. J Evol Biol 25: 1351-1363.

Bowler DE, Benton TG (2005). Causes and consequences of animal dispersal strategies: relating individual behaviour to spatial dynamics. Biol Rev 80: 205-225.

Braendle C, David GK, Brisson JA, Stern DL (2006). Wing dimorphism in aphids. Heredity 97: 192-199.

Cheplick GP (2007). Plasticity of chasmogamous and cleistogamous reproductive allocation in grasses. Aliso 23: 286-294.

Chevin L-M, Lande R, Mace GM (2010). Adaptation, plasticity, and extinction in changing environment: towards a predictive theory. PLoS Biol 8: e1000357.

Clarke AL, Saether B-E, Roskaft E (1997). Sex biases in avian dispersal: a reappraisal. Dikos 79: 429-438.

Clobert J, Le Galliard J-F, Cote J, Meylan S, Massot M (2009). Informed dispersal, heterogeneity in animal dispersal syndromes and the dynamics of spatially structured populations. Ecol Lett 12: 197-209.

Craig JK, Foote CJ, Wood CC (2005). Countergradient variation in carotenoid use between sympatric morphs of sockeye salmon (Oncorhynchus nerka) exposes nonanadromous hybrids in the wild by their mismatched spawning colour. Biol J Linn Soc 84: 287-305.

Crispo E (2007). The Baldwin effect and genetic assimilation: revisiting two mechanisms of evolutionary change mediated by phenotypic plasticity. Evolution 61: 2469-2479.

Davis JM, Stamps JA (2004). The effect of natal experience on habitat preference. Trends Ecol Evol 19: 411-416.

Deere KA, Grether GF, Sun A, Sinsheimer JS (2012). Female mate preference explains countergradient variation in the sexual coloration of guppies (Poecilia reticulata). Proc Biol Sci 279: 1684-1690.

Donohue K, Pyle EH, Messiqua D, Heschel MS, Schmitt J (2001). Adaptive divergence in plasticity in natural populations of Impatiens capensis and its consequences for performance in novel habitats. Evolution 55: 692-702.

Edelaar P, Bolnick DI (2012). Non-random gene flow: an underappreciated force in evolution and ecology. Trends Ecol Evol 27: 659-665.

Edelaar P, Siepielski AM, Clobert J (2008). Matching habitat choice causes directed gene flow: a neglected dimension in evolution and ecology. Evolution 62: 2462-2472.

Fairbairn DJ, King E (2009). Why do California striders fly? J Evol Biol 22: 36-49.

Fitzpatrick BM (2012). Underappreciated consequences of phenotypic plasticity for ecological speciation. Int J Ecol 2012: doi:10.1155/2012/256017.

Franhofer EA, Stelz JM, Poethke HJ, Bonte D (2014). Spatially correlated extinctions select for less emigration but larger dispersal distance in the spider mite Tetranychus urticae. Evolution 68: 1838-1844.

Garant D, Kruuk LEB, Wilkin TA, McCleery RH, Sheldon BC (2005). Evolution driven by differential dispersal within a wild bird population. Nature 433: 60-65.

Garant D, Forde SE, Hendry AP (2007). The multifarious effects of dispersal and gene flow on contemporary adaptation. Funct Ecol 21: 434-443.

Garroway CJ, Radersma R, Sepil I, Santure AW, De Cauwer I, Slate J et al. (2013) Fine-scale genetic structure in a wild bird population: the role of limited dispersal and environmentally based selection as causal factors. Evolution 67: 3488-3500.

Ghalambor CK, McKay JK, Carroll SP, Reznick DN (2007). Adaptive versus non-adaptive phenotypic plasticity and the potential for contemporary adaptation in new environments. Funct Ecol 21: 394-407.

Gibson GD, Gibson AJF (2004). Heterochrony and the evolution of poecilogony: generating larval diversity. Evolution 58: 2704-2717.

Grant PR, Grant BR (2014). 40 Years of Evolution: Darwin's finches on Daphne Major Island. Princeton University Press: Princeton, NJ, USA.

Grether GF (2005). Environmental change, phenotypic plasticity, and genetic compensation. Am Nat 166: E115-E123.

Harrison RG (1980). Dispersal polymorphisms in insects. Annu Rev Ecol System 11: 95-118.

Havens JA, Etges WJ (2013). Premating isolation is determined by larval rearing substrates in cactophilic Drosophila mojavensis. IX. Host plant and population specific epicuticular hydrocarbon expression influences mate choice and sexual selection. J Evol Biol 26 562-576.

Hazel W, Smock R, Lively CM (2004). The ecological genetics of conditional strategies. Am Nat 163: 888-900.

Hedrick PW (1986). Genetic polymorphisms in heterogeneous environments: a decade later. Annu Rev Ecol Syst 17: 535-566.

Heinz SK, Mazzucco R, Dieckmann U (2009). Speciation and the evolution of dispersal along environmental gradients. Evol Ecol 23: 53-70.

Hendry AP, Taylor EB, McPhail JD (2002). Adaptive divergence and the balance between selection and gene flow: lake and stream stickleback in the Misty system. Evolution 56: 1199-1216.
Hendry AP, Taylor EB (2004). How much of the variation in adaptive divergence can be explained by gene flow? An evaluation using lake-stream stickleback pairs. Evolution $\mathbf{5 8}$ 2319-2331.

Huffacker CB (1958). Experimental studies on predation: dispersion factors and predator-prey oscillations. Hilgardia 27: 343-383.

Imbert $E$ (1999). The effects of achene dimorphism on the dispersal in time and space in Crepis sancta (Asteraceae). Can J Bot 77: 508-513.

Imbert E, Ronce O (2001). Phenotypic plasticity for dispersal ability in the seed heteromorphic Crepis sancta (Asteraceae). Oikos 93: 126-134.

Johnson ML, Gaines MS (1990). Evolution of dispersal: theoretical models and empirica tests using birds and mammals. Annu Rev Ecol Syst 21: 449-480.

Johst K, Brandl R (1997). The effect of dispersal on local population dynamics. Ecol Model 104: 87-101.

Krug PJ, Gordon D, Romero MR (2012). Seasonal polyphenism in larval type: rearing environment influences the development mode expressed by adults in the sea slug Alderia willowi. Integr Comp Biol 52: 161-172.

Lavergne S, Molofsky J (2007). Increased genetic variation and evolutionary potential drive the success of an invasive grass. Proc Natl Acad Sci USA 104: 3883-3888.

Levin LA, Zhu J, Creed E (1991). The genetic basis of life-history characters in a polychaete exhibiting planktotrophy and lecithotrophy. Evolution 45: 380-397.

Li J, Margolies DC (1994). Responses to direct and indirect selection on aerial dispersal behaviour in Tetranychus urticae. Heredity 72: 10-22.

Lidicker Jr WZ, Stenseth NC (1992). To disperse or not to disperse: who does it and why? In: Stenseth NC, Lidicker WZ Jr (eds). Animal Dispersal: small mammals as a model. Chapman \& Hall: London, UK. pp 21-36.

Lima SL, Zollner PA (1996). Towards a behavioral ecology of ecological landscapes. Trends Ecol Evol 11: 131-135.

Martorell C, Martinez-Lopez M (2014). Informed dispersal in plants: Heterosperma pinnatum (Asteraceae) adjusts its dispersal mode to escape from competition and water stress. Oikos 123: 225-231.

McPeek MA, Holt RD (1992). The evolution of dispersal in spatially and temporally varying environments. Am Nat 140: 1010-1027.

Morgan TS, Rogers AD, Paterson GLJ, Hawkins LE, Sheader M (1999). Evidence for poecilogony in Pygospio elegans (Polychaeta: Spionidae). Mar Ecol Prog Ser 178: 121-132

Paenke I, Sendhoff B, Kawecki TJ (2007). Influence of plasticity and learning on evolution under directional selection. Am Nat 170: E47-E58.

Payne JL, Mazzucco R, Dieckmann U (2011). The environmental dispersal and reproductive isolation along environmental gradients. J Theor Biol 273 $147-155$.

Petren K (2013). The evolution of landscape genetics. Evolution 67: 3383-3385.

Pfennig DW, Wund MA, Snell-Rood EC, Cruickshank T, Schlichting CD, Moczek AP (2010). Phenotypic plasticity's impacts on diversification and speciation. Trends Ecol Evol 25 459-467.

Pfennig DW, McGee M (2010). Resource polyphenism increases species richness: a test of the hypothesis. Philos Trans R Soc Lond B Biol Sci 365: 577-591.

Poniatowski D, Fartmann T (2009). Experimental evidence for density-determined wing dimorphism in two bush-crickets (Ensifera: Tettigoniidae). Eur J Entomol 106 599-605

Postma E, van Noordwijk AJ (2005). Gene flow maintains a large genetic difference in clutch size at a small spatial scale. Nature 433: 65-68.

Price T, Qvarnstrom A, Irwin DE (2003). The role of phenotypic plasticity in driving genetic evolution. Proc Biol Sci 270: 1433-1440.

Ravigne V, Olivieri I, Dieckmann U (2004). Implications of habitat choice for protected polymorphisms. Evol Ecol Res 6: 125-145.

Ravigne V, Dieckmann U, Olivieri I (2009). Live where you thrive: joint evolution of habitat choice and local adaptation facilitates specialization and promotes diversity. Am Nat 174: E141-E169.

Real L (1990). Search theory and mate choice. I. Models of single-sex discrimination. Am Nat 136: 376-405.

Rieseberg LH, Raymond O, Rosenthal DM, Lai Z, Livingston K, Nakazato T et al. (2003). Major ecological transitions in wild sunflowers facilitated by hybridization. Science $\mathbf{3 0 1}$ $1211-1216$

Roff DA (1986). The evolution of wing dimorphism in insects. Evolution 40: 1009-1020.

Ronce $O$ (2007). How does it feel to be like a rolling stone? Ten questions about dispersal evolution. Annu Rev Ecol Evol Syst 38: 231-253.

Scheiner SM (1998). The genetics of phenotypic plasticity. VII. Evolution in a spatiallystructured environment. J Evol Biol 11: 303-320.

Schlichting CD, Pigliucci M (1998). Phenotypic Evolution: A Reaction Norm Perspective. Sinauer Associates, Inc.: Sunderland.

Schlichting CD (2004). The role of phenotypic plasticity in diversification. In: DeWitt TJ, Scheiner SM (eds). Phenotypic Plasticity: functional and conceptual approaches. Oxford University Press: New York, NY, USA. pp 191-200.

Schmitt J, Wulff RD (1993). Light spectral quality, phytochrome and plant competition. Trends Ecol Evol 8: 47-51.

Soons MB, Heil GW, Nathan R, Katul GG (2004). Determinants of long-distance seed dispersal by wind in grasslands. Ecology 85: 3056-3068.

Stamps JA, Krishnan VV, Reid ML (2005). Search costs and habitat selection by dispersers. Ecology 86: 510-518.

Stamps JA (2006). The silver spoon effect and habitat selection by natal dispersers. Ecol Lett 9: 1179-1185.

Stamps JA, Swaisgood RR (2007). Someplace like home: experience, habitat selection and conservation biology. Appl Anim Behav Sci 102: 392-409. 
Thibert-Plante X, Hendry AP (2011). The consequences of phenotypic plasticity for ecological speciation. J Evol Biol 24: 326-342.

Thomson FJ, Moles AT, Auld TD, Kingsford RT (2011). Seed dispersal distance is more strongly correlated with plant height than with seed mass. J Ecol 99. 1299-1307.

Titus RG, Mosegaard H (1991). Selection for growth potential among migratory brown trout (Salmo trutta) fry competing for territories: evidence from otoliths. Can J Fish Aquat Sci 48: 19-26.

Travis JMJ, Murrell DJ, Dytham C (1999). The evolution of density-dependent dispersal. Proc Biol Sci 266: 1837-1842.
Vuilleumier S, Perrin N (2006). Effects of cognitive abilities on metapopulation connectivity. Oikos 113: 139-147.

Weinig C, Gravuer KA, Kane NC, Schmitt J (2004). Testing adaptive plasticity to UV: costs and benefits of stem elongation and light-induced phenolics. Evolution 58: 2645-2656. West-Eberhard MJ (1989). Phenotypic plasticity and the origins of diversity. Annu Rev Ecol Syst 20: 249-278.

West-Eberhard MJ (2003). Developmental Plasticity and Evolution. Oxford University Press: Oxford.

Zera AJ (2004). The endocrine regulation of wing polymorphism in insects: state of the art, recent surprises, and future directions. Integr Comp Biol 43: 607-626. 